\title{
Identification and evaluation of enzymatic ability of fungal endophytes from Citrofortunella microcarpa (Bunge) Wijnands
}

\author{
Reyes RDC, Parayao AM and Waing KGD
}

Department of Biological Sciences, College of Science, Central Luzon State University, 3120 Science City of Muñoz, Nueva Ecija, Philippines

Reyes RDC, Parayao AM, Waing KGD 2021 - Identification and evaluation of enzymatic ability of fungal endophytes from Citrofortunella microcarpa (Bunge) Wijnands. Studies in Fungi 6(1), 460468, Doi 10.5943/sif/6/1/35

\begin{abstract}
Citrofortunella microcarpa locally known as "kalamansi" belongs to the family Rutaceae is one of the most important marketable fruit crops grown in the Philippines. Aside from being a fruit crop, the plant also houses various endophytic microorganisms which exhibit various symbiotic relationships. Thus, this study isolated fungal endophytes from $C$. microcarpa stem and leaves and were identified culturally and morphologically. The identities of the fungal species were confirmed using ITS1 and ITS4 sequences. The identified fungal endophytes were tested for their ability to produce fungal enzymes such as amylase, cellulase, laccase and protease. Totally 11 fungal endophytes were isolated from stem and leaves of C. microcarpa namely, Colletotrichum fructicola, Colletorichum gloeosporioides, Colletotrichum siamense, Fusarium oxysporum, Lasiodiplodia theobromae, Nigrospora oryzae, Nigrospora rubi, Nodulisporium indicum, Phomopsis azadirachtae, Phyllosticta capitalensis, and an unidentified species under the Order Pleosporales. All the identified endophytic fungal species showed production of amylase. For the cellulose assay, four species namely $L$. theobromae, $N$. oryzae, $C$. gloeosporioides, and the unidentified species had potential for cellulose degradation. Fusarium oxysporum and $P$. azadirachtae were found to be producers of laccase. Meanwhile, only the unidentified species showed extracellular protease activity.
\end{abstract}

Keywords - enzymes - extracellular - ITS primers - Pleosporales

\section{Introduction}

Citrofortunella microcarpa locally known as "kalamansi" belonging to the family Rutaceae, is one of the most important commercial fruit crops grown in the Philippines and used condiment in almost every famous dish (Morte et al. 2017). It is characterized as small tree with smooth, oblong to broadly lanceolate, and narrowly winged short petioled leaves (Dulay \& De Castro 2016). Aside from being a fruit crop, this plant also houses various endophytic microorganisms that are found in wide variety of plant tissues such as seeds, ovules, fruits, stems, roots, leaves, tubers, buds, xylem and bark. Endophytic microorganisms are inhabitants of the internal part of plants, causing apparently no harm to their hosts. It has been also found that some endophytic fungi produce valuable enzymes that are relatively unexplored which are useful to pharmaceutical and agricultural industries producing valuable substances of biotechnological interest (Patel et al. 2013). Enzymes produced by microorganisms are considered as potential biocatalysts for a large number of reactions and are generally regarded as safe and functional at wide range of temperature, $\mathrm{pH}$, salinity or other extreme conditions (Priyadharsini \& Dhanasekaran 2015). Thus, this study was conducted to evaluate the 
enzymatic ability of endophytic fungi isolated from $C$. microcarpa stem and leaves that would provide information on their diversity and ability to produce fungal enzymes such as amylase, cellulose, protease and laccase that is of biotechnological interest.

\section{Materials \& methods}

\section{Isolation of fungal endophytes}

Citrofortunella microcarpa stem and leaves were collected from calamansi plantations in Mayapyap Sur, Cabanatuan City, Nueva Ecija (15³1'05.0"N 12057'48.9"E). Matured and healthy leaves and stem were cleaned of adhering debris and surface sterilized using $70 \%$ ethanol for 1 minute followed by sequential 1-minute washing with solutions containing $1 \%$ sodium hypochlorite, $70 \%$ ethanol and sterile distilled water and allowed to surface dry on filter paper. After proper drying, approximately $1 \times 1 \mathrm{~cm}$ of sterilized leaf and $1 \mathrm{~cm}$ length of stem were inoculated in a previously plated potato dextrose agar (PDA) and incubated at room temperature for 5 days. Then, individual colonies were inoculated onto new PDA plates and repetitive re-plating of the fungal colonies was continued until pure cultures were obtained (Patel et al. 2013). Pure cultures of the identified isolates were deposited at Biodiversity Conservation Laboratory, Department of Biological Sciences, College of Science, Central Luzon State University, Science City of Munoz, Nueva Ecija, Philippines, 3120. Facesoffungi numbers were registered for the fungal cultures as per Jayasiri et al. (2015).

\section{Cultural and morphological characterization of fungal species}

Cultural characteristics such as colony appearances, mycelial textures and pigmentations on both obverse and reverse sides of PDA plates were observed after 7 days of incubation at room temperature. Growth rate via colony diameter were measured, initially standardized at $6 \mathrm{~mm}$ using a cork borer. Trials were repeated three times and in triplicates (Majid et al. 2015). For microscopic observation, slide culture was used to observe the different micro-morphological characteristics of the isolated fungal endophytes (Prakash \& Bhargava 2016).

\section{Molecular identification of fungal endophytes}

Seven-day old cultures of the different fungal isolates grown on PDA medium on test tubes were sent to the Philippine Genome Center in Quezon City, Manila for DNA extraction and sequencing. DNA extraction was done using CTAB method. Gene was amplified by PCR and components include genomic DNA, Universal ITS1 (5'tccgtaggtgaacetgcgg-3') and ITS4 (5'tcctccgettattgatatgc-3') primers, Taq Buffer, DNA Polymerase, and dNTP Mix. Cycling parameters on thermal cycler: $95^{\circ} \mathrm{C} 5 \mathrm{~min} ; 30$ cycles of $95^{\circ} \mathrm{C} 1 \mathrm{~min}, 58^{\circ} \mathrm{C} 45 \mathrm{secs}, 70^{\circ} \mathrm{C} 1 \mathrm{~min} ; 72^{\circ} \mathrm{C} 10 \mathrm{~min}$; hold at $4^{\circ} \mathrm{C}$. Capillary sequencing was carried out on the ABI 3730xl DNA Analyzer using a 50cm 96-capillary array, POP7TM Polymer, and 3730x1. Data Collection Software v3.1 and base calling was done on Sequencing Analysis Software v5.4. Trimming and assembling of sequences was done using Codon Code Aligner V8.0.2. Sequencing was verified by BLASTn and aligned through CLUSTAL W.

\section{Assessment of enzyme producing efficiencies of fungal isolates}

\section{Amylase activity}

Fungal endophytes from $C$. microcarpa were grown on glucose yeast peptone agar (glucose: 1g; yeast extract: $1 \mathrm{~g}$; peptone: $0.5 \mathrm{~g}$; agar: $16 \mathrm{~g}$; d.w.:1000ml; pH 6) medium supplemented with $2 \%$ starch as substrate. Then, plates inoculated with fungal endophytes were incubated at room temperature for 7 days. After incubation, the plates were flooded with $1 \%$ iodine solution. The clear zone formed surrounding the fungal colonies were considered positive for the test (Patel et al. 2013).

\section{Cellulase activity}

Fungal endophytes from $C$. microcarpa were grown on yeast peptone agar medium (yeast 
extract: $1 \mathrm{~g}$; peptone: $0.5 \mathrm{~g}$; agar: $16 \mathrm{~g}$; d.w. $1000 \mathrm{ml}$ ) supplemented with $0.5 \%$ Na-carboxymethyl cellulose (CMC) as enzyme substrate. Then, plates were incubated for 7 days at room temperature. After incubation, the plates were flooded with $0.2 \%$ aqueous solution of Congo red and followed by destaining using $1 \mathrm{M} \mathrm{NaCl}$ solution for $15 \mathrm{~min}$. The clear zone surrounding the colony indicated positive for the test (Patel et al. 2013)

\section{Laccase activity}

Fungal endophytes from $C$. microcarpa were grown on glucose yeast peptone agar medium (glucose: $1 \mathrm{~g}$; yeast extract: $1 \mathrm{~g}$; peptone: $0.5 \mathrm{~g}$; agar: $16 \mathrm{~g}$; d.w.: $1000 \mathrm{ml} ; \mathrm{pH}: 6$ ) amended with $0.005 \%$ 1-naphthol as enzyme substrate. Plates were the incubated at room temperature for 7 days. Oxidation of 1-naphthol by laccase, the culture medium changed from clear to blue. The color change indicated positive for the test (Patel et al. 2013).

\section{Protease activity}

Fungal endophytes from $C$. microcarpa were grown on glucose yeast peptone medium (glucose: 1g; yeast extract; $1 \mathrm{~g}$; peptone; 0.5g; agar; $16 \mathrm{~g}$; d.w.; 1000ml; pH: 6) supplemented with $0.4 \%$ gelatin as enzyme substrate Then, plates inoculated with fungal endophytes were incubated at room temperature for 7 days. After incubation, saturated aqueous ammonium sulphate was used to flood the plates. The digested area surrounding the colonies appeared clear indicating positive for the test (Patel et al. 2013).

\section{Data analysis}

The enzymatic index (EI) were determined by dividing the measured colony diameter $\left(\varnothing_{c}\right)$ and the formed enzymatic halo diameter $(\varnothing \mathrm{h})(E I=\varnothing \mathrm{h} / \varnothing \mathrm{c})$. Samples with computed enzymatic index with 2.0 and higher are considered to have a high rate of enzyme production (Herculano et al. 2011). The halo presence or clear area around the fungal colony were the enzymatic activity indicator evidenced by the enzymes secretion made by fungi through the culture medium (Sharma \& Sumbali 2014).

\section{Statistical analysis}

The enzymatic experiments were laid out on a Completely Randomized Design (CRD). Screening for enzyme activities were analyzed using analysis one-way Analysis of Variance (ANOVA). Comparison among means was done using Duncan multiple range test (DMRT) at 5\% level of significance using IBM SPSS Statistics 2019 Ver. 26 (SPSS Inc., Chicago, USA).

\section{Results}

\section{Cultural and morphological characteristics of fungal endophytes}

A total of 11 fungal endophytes were isolated from stem and leaves of Citrofortunella microcarpa namely; Colletotrichum fructicola, Colletotrichum gloeosporioides, Colletotrichum siamense, Fusarium oxysporum, Lasiodiplodia theobromae, Nigrospora oryzae, Nigrospora rubi, Nodulisporium indicum, Phomopsis azadirachtae, Phyllosticta capitalensis, and an unidentified Pleosporales species. C. fructicola and F. oxysporum were isolated from leaves. $N$. indicum, $L$. theobromae, $P$. azadirachtae, $P$. capitalensis and the unidentified species were isolated from stem. Meanwhile, $N$. oryzae, $C$. siamense, $N$. rubi and $C$. gloeosporioides were isolated both from leaves and stem.

To confirm the identity of the fungal endophytes isolated from $C$. microcarpa, the ITS region was amplified using ITS1 and ITS4 primers and were sequenced. The PCR products of the ITS region in the eleven different fungi were confirmed to be in range of approximately 600-900bp which are characteristics of ITS1 and ITS4 region. Blast analysis revealed that fungal species were identified as $C$. fructicola FoF 06767 with (99.79\%), C. gloeosporioides FoF 09424 (99.79\%), C. siamense FoF 03599 (99.57\%), F. oxysporum FoF 03824 (98.13\%), L. theobromae FoF 00167 (99.02\%), N. oryzae 
FoF 06596 (99.58\%), N. rubi FoF 06598 (99.38 \%), N. indicum FoF 10588 (99.36\%), P. azadirachtae FoF 10589 (98.31\%), P. capitalensis FoF 06888 (99.64\%), and unidentified species FoF10590 (95.83\%), respectively (Table 1.$)$

Table 1 Identities of the cultured fungi based on BLAST search with NCBI Genbank accessions and Facesoffungi numbers

\begin{tabular}{|c|c|c|c|c|c|}
\hline Isolate No. & Facesoffungii Number & Species & E value & Identity & $\begin{array}{l}\text { Gen Bank } \\
\text { Accession No. }\end{array}$ \\
\hline LF01 & FoF 06767 & $\begin{array}{l}\text { Colletotrichum } \\
\text { fructicola }\end{array}$ & 0.00 & $99.79 \%$ & MK041513 \\
\hline LF02 & FoF 03824 & Fusarium oxysporum & 0.00 & $98.13 \%$ & MG543712 \\
\hline STM01 & FoF 00167 & $\begin{array}{l}\text { Lasiodiplodia } \\
\text { theobromae }\end{array}$ & 0.00 & $99.02 \%$ & KF814723 \\
\hline STM02 & FoF 10588 & Nodulisporium indicum & 0.00 & $99.36 \%$ & KJB26516 \\
\hline STM03 & FoF 10589 & Phomopsis azadirachtae & 0.00 & $98.31 \%$ & KR056296 \\
\hline STM05 & FoF 06888 & Phyllosticta capitalensis & 0.00 & $99.64 \%$ & MF153383 \\
\hline STM06 & FoF10590 & Unidentified species & 0.00 & $95.83 \%$ & HM751829 \\
\hline STM/LF01 & FoF 03599 & $\begin{array}{l}\text { Colletotrichum } \\
\text { siamense }\end{array}$ & 0.00 & $99.57 \%$ & MK569274 \\
\hline STM/LF02 & FoF 06596 & Nigrospora oryzae & 0.00 & $99.58 \%$ & KU360637 \\
\hline STM/LF03 & FoF 06598 & Nigrospora rubi & 0.00 & $99.38 \%$ & KX985948 \\
\hline STM/LF04 & FoF 09424 & $\begin{array}{l}\text { Colletotrichum } \\
\text { gloeosporioides }\end{array}$ & 0.00 & $99.79 \%$ & KP900290 \\
\hline
\end{tabular}

$\mathrm{LF}=$ Isolated from leaf, $\mathrm{STM}=$ Isolated from stem

\section{Assessment of enzyme producing efficiencies}

\section{Amylase activity}

The eleven species of endophytic fungi tested were able to produce amylase (Table 2, Fig. 1). $P$. capitalensis had the highest computed enzymatic index which is 3.75 followed by the unidentified species and $N$. oryzae with 1.99 and 1.60 , respectively. Computed values were significantly different from each other. Meanwhile, $N$. indicum, F. oxysporum, L. theobromae, N. rubi, C. siamense and $P$. azadirachtae all have computed enzymatic index of 1.0 which are significantly different from $C$. fructicola.

Table 2 Amylase activity of different fungal endophytes after seven days of incubation

\begin{tabular}{lccc}
\hline Fungal endophytes & \multicolumn{3}{c}{ Amylase } \\
\cline { 2 - 4 } & $\begin{array}{l}\text { Diameter of clear zone } \\
(\mathbf{m m})\end{array}$ & $\begin{array}{l}\text { Colony diameter } \\
(\mathbf{m m})\end{array}$ & $\begin{array}{l}\text { Enzymatic index } \\
(\mathbf{E I})\end{array}$ \\
\hline Nodulisporium indicum & $85.00^{\mathrm{a}}$ & 85.00 & $1.00^{\mathrm{d}}$ \\
Fusarium oxysporum & $85.00^{\mathrm{a}}$ & 85.00 & $1.00^{\mathrm{d}}$ \\
$\begin{array}{l}\text { Lasiodiplodia } \\
\text { theobromae }\end{array}$ & $85.00^{\mathrm{a}}$ & 85.00 & $1.00^{\mathrm{d}}$ \\
Nigrospora rubi & & & \\
Colletotrichum siamense & $85.00^{\mathrm{a}}$ & 85.00 & $1.00^{\mathrm{d}}$ \\
Phomopsis azadirachtae & $85.00^{\mathrm{a}}$ & 85.00 & $1.00^{\mathrm{d}}$ \\
Colletotrichum fructicola & $83.47^{\mathrm{a}}$ & 83.47 & $1.00^{\mathrm{d}}$ \\
Colletotrichum & $75.88^{\mathrm{b}}$ & 75.96 & $0.99^{\mathrm{e}}$ \\
gloeosporioides & $65.80^{\mathrm{c}}$ & 65.80 & $1.00^{\mathrm{d}}$ \\
Nigrospora oryzae & & & \\
Unidentified species & $44.10^{\mathrm{d}}$ & 27.63 & $1.60^{\mathrm{c}}$ \\
Phyllosticta capitalensis & $40.90^{\mathrm{e}}$ & 20.53 & $1.99^{\mathrm{b}}$ \\
\hline
\end{tabular}

Values represent the mean measurements of the clear zones indicating amylase activity produced by the fungal endophytes from Citrofortunella microcarpa. Means with the same letter superscript are not significantly different at $5 \%$ level of significance using DMRT 


\section{Cellulase activity}

A total of four species of endophytic fungi isolated from C. microcarpa namely L. theobromae, $N$. oryzae, C. gloeosporioides and unidentified Pleosporales showed cellulose degradation (Table 3, Fig. 2). The largest enzymatic index was unidentified species with an index of 2.02, second was $C$. gloeosporioides with 1.22 while $L$. theobromae and $N$. oryzae both having 1.06 computed enzymatic index respectively. Meanwhile, $L$. theobromae, and $N$. oryzae were comparable with each other. Only $25 \%$ of the endophytes tested in this study were able to produce cellulose.

\section{Protease Activity}

Among the tested organisms, extracellular protease activity was only observed in unidentified Pleosporales with a clear zone of $31.3 \mathrm{~mm}$ and computed enzymatic index of 1.47 (Fig. 3).

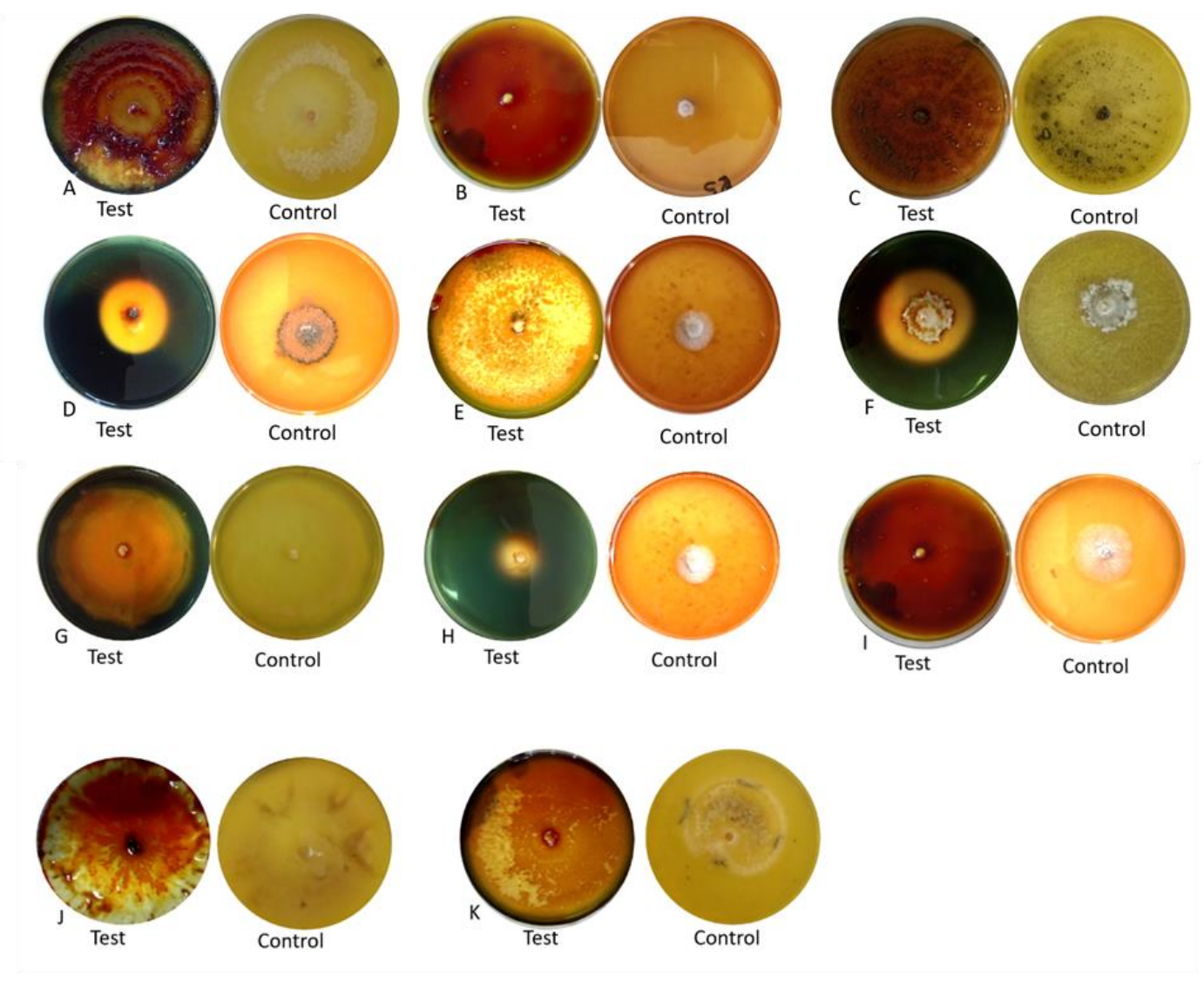

Fig. 1 - Clear zone produced by different fungal endophytes on amylase activity isolated from C. microcarpa. A Colletotrichum fructicola. B Lasiodiplodia theobromae. C Nodulisporium indicum. D Phyllosticta capitalensis. E Colletotrichum siamense. F Nigrospora oryzae. G Colletotrichum gloeosporioides. H unidentified species. I Fusarium oxysporum. J Nigrospora rubi. K Phomopsis azadirachtae.

Table 3 Cellulase activity of different fungal endophytes after seven days of incubation.

\begin{tabular}{lccc}
\hline \multirow{2}{*}{ Fungal endophytes } & \multicolumn{3}{c}{ Cellulase } \\
\cline { 2 - 4 } & $\begin{array}{c}\text { Diameter of clear zone } \\
(\mathbf{m m})\end{array}$ & $\begin{array}{c}\text { Colony diameter } \\
(\mathbf{m m})\end{array}$ & $\begin{array}{c}\text { Enzymatic index } \\
(\mathbf{E I})\end{array}$ \\
\hline Nigrospora oryzae & $80.0^{\mathrm{a}}$ & 75.60 & $1.06^{\mathrm{c}}$ \\
Lasiodiplodia theobromae & $78.4^{\mathrm{b}}$ & 74.20 & $1.06^{\mathrm{c}}$ \\
Colletotrichum gloeosporioides & $74.9^{\mathrm{c}}$ & 61.20 & $1.22^{\mathrm{b}}$ \\
Unidentified species & $25.2^{\mathrm{d}}$ & 12.70 & $2.02^{\mathrm{a}}$ \\
\hline
\end{tabular}


Values represent the mean measurements of the clear zones indicating cellulase activity produced by the fungal endophytes from Citrofortunella microcarpa. Means with the same letter superscript are not significantly different at $5 \%$ level of significance using DMRT

***EI greater than 2.00 has high rate of enzyme production
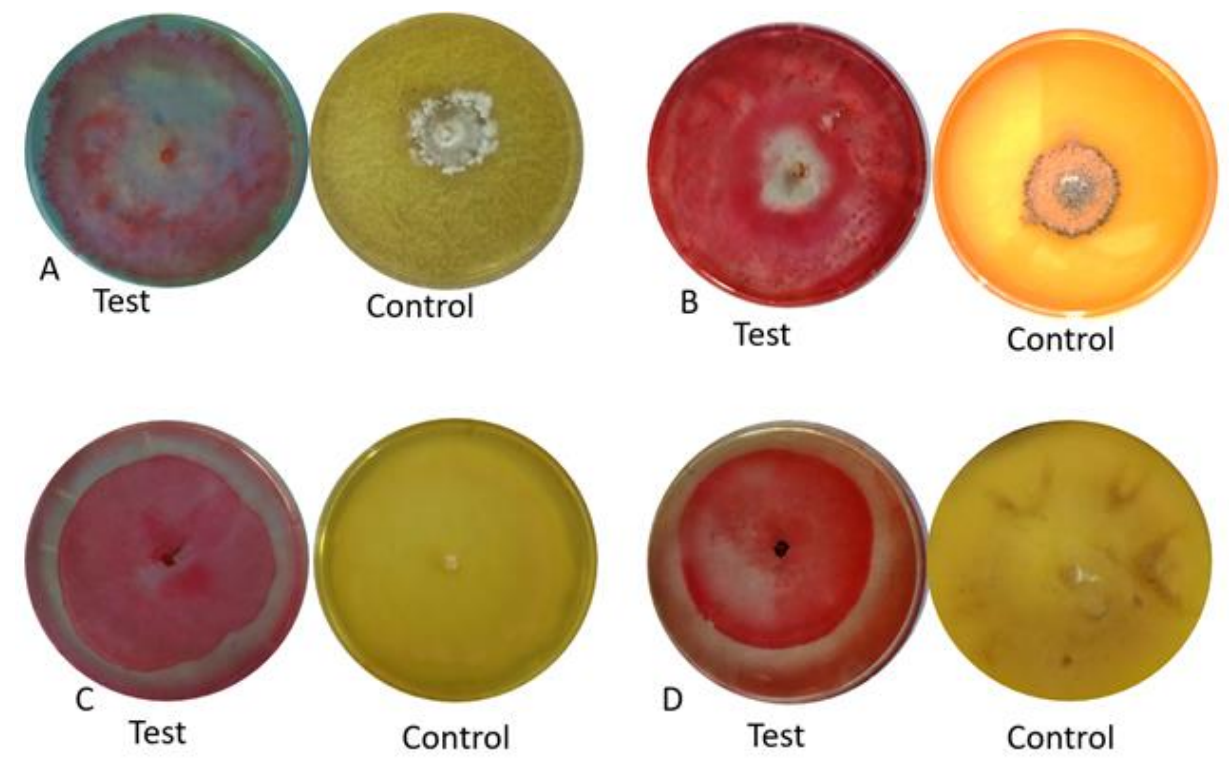

Fig. 2 - Clear zone produced by different fungal endophytes on cellulase activity isolated from Citrofortunella microcarp. A Nigrospora oryzae. B unidentified Pleosporales. C Colletotrichum gloeosporioides. D Lasiodiplodia theobromae.
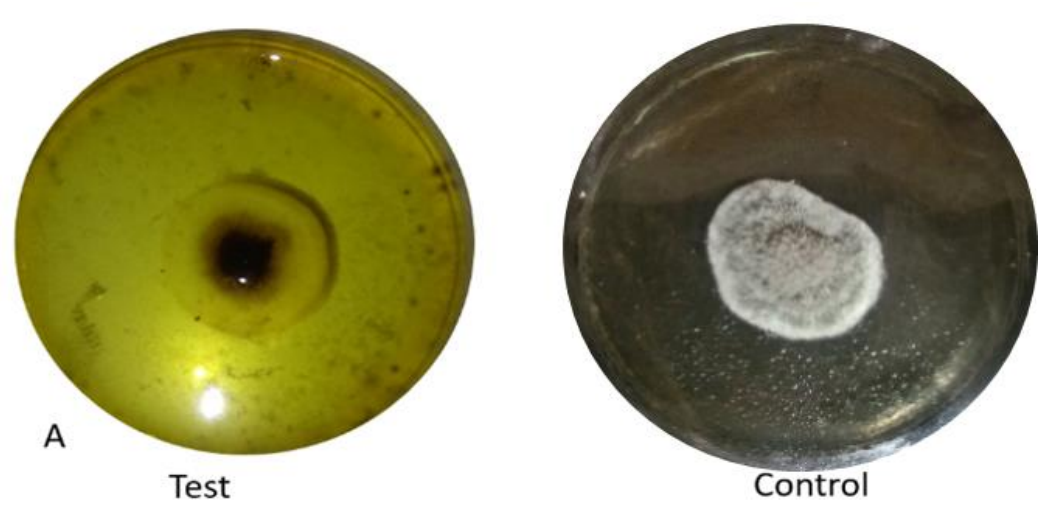

Fig. 3 - Clear zone produced by an unidentified Pleosporales on protease activity.

\section{Laccase Activity}

Fusarium oxysporum and Phomopsis azadirachtae were producers of laccase enzyme (Table 4, Fig. 4). Only two endophytic fungi in this study were able to produce laccase.

Table 4 Laccase activity of different isolated fungal endophytes after seven days of incubation

\begin{tabular}{lc}
\hline \multicolumn{1}{c}{ Fungal endophytes } & Laccase \\
\hline Colletotrichum fructicola & - \\
Colletotrichum gloeosporioides & - \\
Colletotrichum siamense & - \\
Fusarium oxysporum & + \\
Lasiodiplodia theobromae & - \\
Nigrospora oryzae & - \\
Nigrospora rubi & - \\
\hline
\end{tabular}


Table 4 Continued.

\begin{tabular}{lc}
\hline \multicolumn{1}{c}{ Fungal endophytes } & Laccase \\
\hline Nodulisporium indicum & - \\
Phomopsis azadirachtae & + \\
Phyllosticta capitalensis & - \\
Unidentified species & - \\
\hline
\end{tabular}

(+) presence of color change, (-) absence of color change
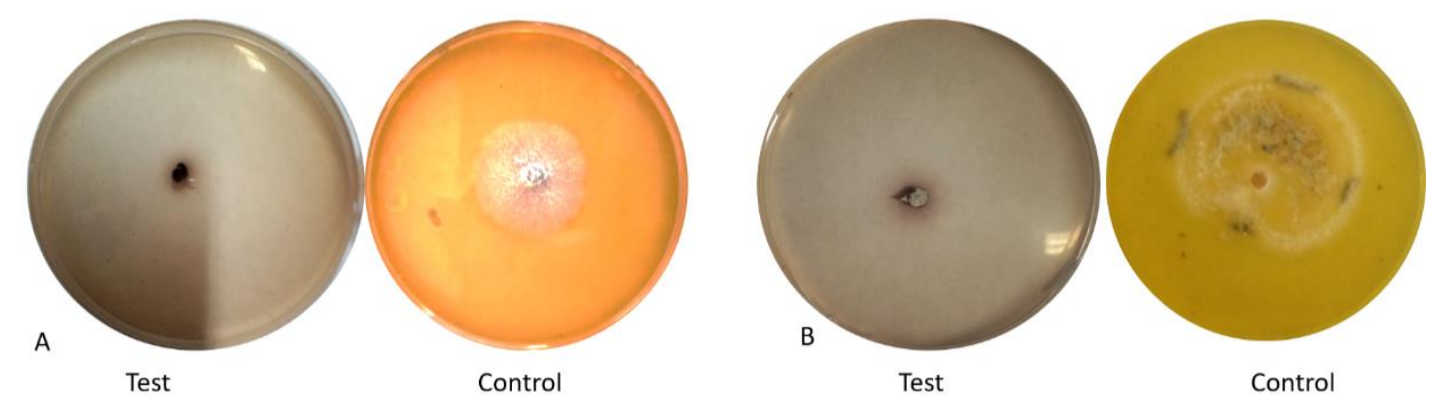

Fig. 4 - Color change produced by fungal endophytes on laccase activity. A Fusarium oxysporum. B Phomopsis azadirachtae.

\section{Discussion}

The role of endophytic fungi in plant decomposition has been demonstrated over several years, since these fungi are present in the senescent tissue, and they are the first ones to initiate plant decomposition (Wilson 2000). Furthermore, Sun et al. (2011) also indicated that endophytes generally decompose dead host leaves, not only as a single species, but also as communities. In this study, 11 fungal endophytes were isolated and identified from both leaves and stem of Citronella microcarpa. These were three species of Colletotrichum, two species of Nigrospora and species each for the genus Fusarium, Lasiodiplodia, Nodulisporium, Phomopsis, Phyllosticta and unidentified Pleosporales which were tested for their enzyme producing abilities.

Endophytes are fungi that asymptomatically colonize plant tissues during some phase of their life cycle (Saikkonen 2007), but may turn pathogenic during host senescence (Rodriguez et al., 2009). The fungal endophytes isolated and identified were found to be associated from various diseases of Citrus. Colletotrichum, Fusarium, and Lasiodiplodia species were found to be associated with citrus diseases in Europe, Mediterranean and Florida (Yaseen \& D'Onghia 2010, Zhang 2014, Guarnaccia et al. 2017a). Also, Phyllosticta and Phomopsis are causal agents of Citrus disease such as the stemend rot and Citrus Black Spot Disease (Gopal et al. 2013, Guarnaccia et al. 2017b). Meanwhile, Nodulisporium produced antifungal volatile compounds that can control green mold decay on Citrus limon (Suwannarach et al. 2013) while Nigrospora, a ubiquitious endophytes, have been studied for the discovery of novel metabolites (Wang et al. 2017). Describing the niche and ecological role of endophytes are complicated because identical fungal species have been labelled as endophytic or pathogenic depending on the basis of the study and whether the study examines asexual or sexual stage of the fungal species (Ahlholm et al. 2002).

One of the most important enzymes used in biotechnology involved in starch hydrolysis are amylases. Amylases produced by various fungi have vast application in food and medicine production such as baking, brewing, preparation of digestive aids (Couto \& Sanromán 2006). As a result of the amylase test, all fungal endophytes isolated and identified were able to degrade starch. Based on the studies of Venkatesagowda et al. (2012) they have found out that Colletotrichum gloeosporioides, Fusarium oxysporum and Lasiodiplodia theobromae produce amylolytic activity.

Cellulolytic microorganisms play an important role in the biosphere by recycling cellulose, the most abundant renewable carbohydrate produced by plants through the mechanism of photosynthesis (Qin et al. 2010). N. oryzae, and the unidentified species were able to show cellulose degredation 
similar with the results of the previous study by Qin et al. (2010). Moreover, cellulase activity was also detected on C. gloeosporioides and L. theobromae (Toghueo et al. 2017).

Proteases are one of the major enzymes utilized widely as detergents, used in leather, food and pharmaceutical industries and for bioremediation processes (Najafi et al. 2005). Proteolytic enzymes play an important role in fungal physiology and development (Yike 2011).

Laccase is blue copper dependent oxidases which is a main ligninolytic enzyme produced by white rot fungus and catalyzing the oxidation of large numbers of phenolic compound (Poonkuzhali et al. 2011). Fungal laccases have boundless biotechnological functions such as discoloration and detoxification of industrial effluent, bleaching of pulp, phenolics elimination from wine and many others (Yaver et al. 2001). Only two endophytic fungi in this study were able to produce laccase, similar to the results of Sunitha et al. (2013), showing that species of Fusarium and Phomposis showed laccase activity.

\section{References}

Ahlholm J, Helander ML, Elamo P, Saloniemi I et al. 2002 - Micro-fungi and invertebrate herbivores on birch trees: fungal mediated plant-herbivore interactions or responses to host quality. Ecology Letters 5, 648-655.

Couto SR, Sanromán MA. 2006 - Application of solid-state fermentation to food industry - A review. Journal of Food Engineering 76, 291-302.

Dulay R, De Castro M. 2016 - Antibacterial and antioxidant activities of three Citrus leaves extracts. Scholars Research Library 8(13), 167-170.

Jayasiri SC, Hyde KD, Ariyawansa HA, Bhat J et al. 2015 - The Faces of Fungi database: fungal names linked with morphology, phylogeny and human impacts. Fungal Diversity 74(1): 3-18. Doi 10.1007/s13225-015-0351-8

Gopal K, Mukunda Lakshmi L, Sarada G, Nagalakshmi T et al. 2014 - Citrus melanose (Diaporthe citri Wolf): a review. International Journal of Current Microbiology and Applied Sciences 3(4), 113-124.

Guarnaccia V, Groenewald JZ, Polizz G, Crous PW. 2017a - High species diversity in Colletotrichum associated with citrus diseases in Europe. Persoonia 39, 32-50.

Guarnaccia V, Groenewald JZ, Li H, Glienke C et al. 2017b - First report of Phyllosticta citricarpa and description of two new species, $P$. paracapitalensis and $P$. paracitricarpa from citrus in Europe. Studies in Mycology 87, 161-185,

Herculano P, Lima D, Fernandes M, Neves R et al. 2011 - Isolation of cellulolytic fungi from waste of castor (Ricinus communis L.). Current Microbiology 62, 1416-1422.

Majid A, Zahran Z, Hafis A, Rahim A et al. 2015 - Morphological and molecular characterization of fungus isolated from tropical bedbugs in northern peninsular malaysia, Cimex hemipterus (Hemiptera: cimicidae). Asian Pacific Journal of Tropical Biomedicine 5(9), 707-713.

Morte T, Ed D, Acero L. 2017 - Potential of calamansi (Citrofortunella microcarpa) fruit peels extract in lowering the blood glucose level of streptozotocin induced albino rats (Rattus albus). International Journal of Food Engineering 3(1), 29-34.

Najafi MF, Deobagkar D, Deobagkar D. 2005 - Potential application of protease isolated from Pseudomonas aeruginosa PD100. Electron Journal of Biotechnology 8, 20.

Patel C, Yadav S, Rahi S, Anuradaha D. 2013 - Studies on biodiversity of fungal endophytes of indigenous monocotaceous and dicotaceous plants and evaluation of their enzymatic potentialities. International Journal of Scientific and Research Publications 3(7), 2250-3153.

Poonkuzhali K, Sathishkumar P, Boopathy R, Pal-vannan T. 2011 - Aqueous state laccase thermostabilization using carbohydrate polymers: effect on toxicity assessment of azo dye. Carbohydrate Polymers 85, 341-348.

Prakash P, Bhargava K. 2016 - A modified micro chamber agar spot slide culture technique for microscopic examination of filamentous fungi. Journal of Microbiological Methods 123, 126129 
Priyadharsini P, Dhanasekaran D. 2015 - Diversity of soil allelopathic actinobacteria in Tiruchirappalli District, Tamilnadu, India. Journal of the Saudi Society of Agricultural Sciences 14(1), 54-60.

Promputtha I, Lumyong S, Dhanasekaran V, Mckenzie EHC et al. 2007 - A phylogenetic evaluation of whether endophytes become saprotrophs at host senescence. Microbial Ecology 53, 579590.

Qin Y, He H, Nan L, Min L, Liang Z. 2010 - Isolation and characterization of a thermostable cellulase-producing Fusarium chlamydosporum. World Journal of Microbiology and Biotechnology 26, 1991-1997.

Rodriguez R, White J, Arnold A, Redman R. 2009 - Fungal endophytes: diversity and functional roles. New Phytologist 182 (2), 314-330.

Saikkonen K. 2007 - Forest structure and fungal endophytes. Fungal Biol Rev. 21(3), 67-74

Sharma S, Sumbali G. 2014 - Isolation and screening of cellulolytic fungal species associated with lower denomination currency notes, circulating in Jammu City (India). International Journal of Recent Scientific Research 5(3), 596-600

Sunitha D, Devi N, Srinivas C. 2013 - Extracellular enzymatic activity of endophytic fungal strains isolated from medicinal plants. World Journal of Agricultural Sciences 9(1), 1-9.

Sun X, Guo LD, Hyde KD. 2011 - Community composition of endophytic fungi in Acer truncatum and their role in decomposition. Fungal Diversity 47, 85-95.

Suwannarach N, Kumla J, Bussaban B, Nuangmek W et al. 2013 - Biofumigation with the endophytic fungus Nodulisporium spp. CMU-UPE34 to control postharvest decay of Citrus fruit. Crop Protection 45, 63-70.

Toghueo RMK, Zabalgogeazcoa I, Vázquez De Aldana BR, Boyom FF. 2017 - Enzymatic activity of endophytic fungi from the medicinal plants Terminalia catappa, Terminalia mantaly and Cananga odorata. South African Journal of Botany 109, 146-153.

Wilson D. 2000 - Ecology of woody plant endophytes. In microbial endophytes. Marcel Dekker, Inc.: New York, pp. 389-420.

Wang M, Liu F, Crous PW, Cai L. 2017 - Phylogenetic reassessment of Nigrospora: ubiquitous endophytes, plant and human pathogens. Persoonia 39, 118-142.

Venkatesagowda B, Ebenezer P, Barbosa A, Dekker M, Robert FH. 2012 - Diversity of plant oil seed-associated fungi isolated from seven oil-bearing seeds and their potential for the production of lipolytic enzymes. World Journal Microbiology Biotechnology 28(1), 71-80.

Yaseen T, D'Onghia A. 2010 - Fusarium spp. associated to citrus dry root rot: an emerging issue for Mediterranean citriculture. Acta Horticulturae 940.

Yaver DS, Berka RM, Brown SH, Xu F. 2001 - The pre symposium on recent advances in lignin biodegradation and biosynthesis. World Journal of Pharmaceutical and Life Sciences 2(2), 221228.

Yike I. 2011 - Fungal proteases and their pathophysiological effects. Mycopathologia 171(5), 299323.

Zhang J. 2014 - Lasiodiplodia theobromae in Citrus fruit (Diplodia Stem-End Rot). Postharvest Decay, Academic Press. Pp. 309-335. 